\title{
O POVO NOVO BRASILEIRO: mestiçagem e identidade no pensamento de Darcy Ribeiro
}

\author{
Flávio Raimundo Giarola*
}

\section{Resumo}

Este artigo analisa a obra de Darcy Ribeiro, sobretudo o livro O Povo Brasileiro (1995), enfocando a relação entre mestiçagem e identidade no pensamento do autor. Pretende entender como o Brasil é identificado enquanto um povo novo, ou seja, uma entidade étnica ímpar, surgida da mistura de povos distintos e com diferentes características raciais, culturais e linguisticas. Assim, a intensa mestiçagem, tanto biológica quanto cultural, aparece como elemento fundamental para se entender a formação do que viria a ser os brasileiros, sendo determinante na formação específica de sua identidade étnica.

Palavras-chave: Darcy Ribeiro. Mestiçagem. Identidade.

\section{Introdução}

Em As Américas e a Civilização (1970), o antropólogo Darcy Ribeiro (1922-1997) ${ }^{1}$ definira Povos-Novos como povos que se constituíram "pela confluência de contingentes profundamente díspares em suas características raciais, culturais e linguísticas, como um subproduto de projetos coloniais europeus” (RIBEIRO, 1983, p. 92). Segundo o autor, a reunião de negros, brancos e índios para abrir grandes plantações de produtos tropicais ou para a exploração mineira, visando atender aos mercados europeus e gerar lucros, acabou por formar povos profundamente diferenciados de si mesmos e de todas as outras matrizes

\footnotetext{
* Doutorando em História pela Universidade Federal de Minas Gerais. E-mail: flaviogiarola@yahoo.com.br

${ }^{1}$ Darcy Ribeiro nasceu em 1922 em Montes Claros, Minas Gerais. Em 1946, formou-se em ciências sociais pela Escola de Sociologia e Política de São Paulo, onde se especializou em etnologia. Criou, na Universidade do Brasil, o primeiro curso de pós-graduação em antropologia, onde lecionou até 1956. Foi um dos fundadores e primeiro reitor da Universidade de Brasília (1962-63). Durante o governo João Goulart, foi ministro da Educação e Cultura e chefe da Casa Civil. Após o golpe militar de 1964, se exilou em vários países da América Latina, voltando em 1976. Foi vice-governador do Rio de Janeiro (1982) e senador (1992). Eleito pela Academia Brasileira de Letras em 1992, faleceu em 1997, em Brasília, vitimado por um câncer (BOTELHO, 2009, p. 430).
} 
formadoras (RIBEIRO, 1983, p. 92). Deste modo, a feição básica destes povos é mestiça, tanto em seus aspectos raciais quanto culturais.

Para Ribeiro, nesse encontro de povos surgiram "línguas francas como instrumentos indispensáveis de comunicação e se plasmaram culturas sincréticas feitas de pedaços tomados dos diferentes patrimônios que melhor se ajustavam a suas condições de vida” (RIBEIRO, 1983, p. 92). Estes Povos-Novos, no entanto, não são nacionalidades multiétnicas, visto que, em todos os casos, houve um processo de formação violento o suficiente para compelir a fusão das matrizes originais em novas unidades homogêneas (RIBEIRO, 1983, p. 93).

Na violência desse processo, a escravidão aparece como elemento decisivo, pois, operando de forma destribalizadora, desgarrava as "novas criaturas" das tradições ancestrais para transformá-las no subproletariado da sociedade nascente:

Nesse sentido, os Povos-Novos são produto, tanto da deculturação redutora de seus patrimônios tribais indígenas africanos, quanto da aculturação seletiva desses patrimônios e da sua própria criatividade face ao novo meio (RIBEIRO, 1983, p. 94).

Portanto, os Povos-Novos resultam da desindianização do índio, da desafricanização do negro e da deseuropeirização do branco. Assim, na América Latina, Darcy Ribeiro identifica como Povos-Novos os brasileiros, os antilhanos, os colombianos e os venezuelanos. Também os chilenos e os paraguaios, que não tiveram uma presença marcante dos negros em sua formação, constituindo uma variante predominantemente índio-espanhola.

Entretanto, os brasileiros parecem ter sido o exemplo mais perfeito desse tipo de formação étnica, o que é amplamente demonstrado no livro O Povo Brasileiro (1995). Dito isto, o presente artigo visa, por um lado, analisar a importância da miscigenação na interpretação do Brasil de Darcy Ribeiro, fator fundamental para a identificação do país como um povo novo. Por outro, pretende demonstrar como, na obra do autor supracitado, a mestiçagem aparece como elemento essencial para se entender a constituição de uma identidade étnica e de um caráter específico da população brasileira.

\section{A formação do Brasil mestiço: gestação étnica e fusão racial na obra de Darcy Ribeiro}

A mistura racial e os mestiços são peças indispensáveis para se entender a obra de Darcy Ribeiro, sobretudo no que tange à sua visão de Brasil. Como afirma Pedro Abib, o antropólogo mineiro, em O Povo Brasileiro, faz uma abordagem sobre o Brasil que defende a 
tese da miscigenação como fator preponderante da diversidade social e cultural que caracterizam nosso país, enquanto possuidor de uma idiossincrasia única e complexa, que nos diferencia de qualquer sociedade desse planeta (ABIB, s/d, p. 3). Deste modo, nessa confluência que se dá sobre a regência dos portugueses, matrizes raciais díspares, tradições culturais distintas e formações sociais defasadas se enfrentam e se fundem para dar lugar a um povo novo (ABIB, s/d, p. 3).

Essa fusão biológica e cultural, na perspectiva de Darcy Ribeiro, teria se iniciado logo que os primeiros portugueses desembarcaram na América, sendo que a gestação étnica do brasileiro se alongaria por todo o período colonial. A miscigenação entre portugueses e indígenas poderia ser explicado tanto por fatores favoráveis pelo lado dos europeus quanto pelo lado dos ameríndios.

Com relação aos portugueses, o antropólogo concorda, em parte, com Gilberto Freyre (1900-1987), ao citar a propensão dos povos ibéricos em se misturarem racialmente com outros povos $^{2}$. Ribeiro afirma que os povos iberos desembarcavam sempre desabusados, acesos e atentos aos mundos novos, querendo fluí-los, recriá-los, convertê-los e mesclar-se racialmente com eles: "Multiplicaram-se, em conseqüência, prodigiosamente, fecundando ventres nativos e criando novos gêneros humanos” (RIBEIRO, 2006, p. 60).

Entretanto, Darcy Ribeiro afasta-se do intelectual pernambucano ao afirmar que, no mundo inteiro, onde quer que o europeu tenha se deparado com gente de cor, em ausência de mulheres brancas, ocorreu um intercurso sexual inter-racial ${ }^{3}$. Assim, segundo o autor, em todo lugar onde povos racialmente diferenciados entraram em contato, gerou-se uma camada mestiça maior ou menor. Portanto, o que diferenciaria as condições de mestiçagem no Brasil das outras áreas é o desenvolvimento de expectativas reciprocamente ajustadas, ou seja, mais incentivadoras do que condenatórias do intercurso: "O nascimento de um filho mulato nas condições brasileiras não é nenhuma traição à matriz negra ou à branca, chegando mesmo a ser motivo de especial satisfação” (RIBEIRO, 2006, p. 60). Ribeiro acredita que essa ideologia integracionista encorajadora do caldeamento seja o valor mais positivo da fusão inter-racial brasileira.

\footnotetext{
${ }^{2}$ Para Gilberto Freyre (1990, p. 9), o longo contato com os sarracenos, durante a ocupação da Península Ibérica pelos mouros, deixava idealizada entre os portugueses a figura da moura-encantada, tipo "delicioso" de mulher morena e de olhos pretos, envolta em misticismo sexual que os colonizadores vieram encontrar parecido, quase igual, entre as índias nuas e de cabelos soltos do Brasil.

${ }^{3}$ Darcy Ribeiro (2006, p. 217) toma como exemplo a África do Sul, onde ingleses ou holandeses e mulheres hotentotes se mesclaram por longo tempo, gerando uma vasta camada mestiça que continuou até que a população branca se homogeneizasse pela composição equilibrada de homens e mulheres. Por outro lado, assinala o autor que as relações entre brancos e escravas negras registram-se em todas as áreas e não apenas nas de colonização portuguesa, como no caso dos mestiços norte-americanos.
} 
Pelo lado dos ameríndios, Darcy Ribeiro destaca a importância do cunhadismo, instituição indígena que consistia na prática de se dar uma moça índia como esposa. Com isso, se estabelecia mil laços que ligavam o estrangeiro com todos os membros do grupo ${ }^{4}$. Em sua função civilizatória, o cunhadismo fez surgir a numerosa camada de indivíduos mestiços que ocupou efetivamente o Brasil. Nesse sentido, funcionou como um criatório de gente miscigenada nas regiões onde "náufragos” e “degradados”, vindos da Europa, se assentaram (RIBEIRO, 2006, p. 73).

Essa miscigenação favorecida pelo cunhadismo teve em São Paulo o seu primeiro e principal centro de desenvolvimento. Nessa região, onde a captura de índios para servirem de escravos tornou-se a principal atividade econômica, surgiram os brasilíndios ou mamelucos, peças fundamentais, segundo Ribeiro, na formação étnica do brasileiro e na expansão territorial do país: "Gerados por pais brancos, a maioria deles lusitanos, sobre mulheres índias, dilataram o domínio português exorbitando a dação de papel das Tordesilhas, excedendo a tudo que se podia esperar” (RIBEIRO, 2006, p. 95).

Assim, foram destes brasilíndios paulistas que saíram os bandeirantes, homens que transformaram o ofício de caçadores de índios em um modo de vida, “em cujo desempenho se fizeram respeitáveis, destacando-se com altas honras, a seus próprios olhos, os mais valentes e briosos” (RIBEIRO, 2006, p. 96). Ribeiro transita entre a admiração pela obra de expansão territorial levada a cabo por estes homens e o repúdio ao extermínio dos povos indígenas empreendido pelas bandeiras. No entanto, mais importante para o autor foi o papel determinante que a composição mestiça dos paulistas exerceu na formação da população brasileira.

Em São Paulo percebeu-se a edificação, com gente desgarrada das tribos, de uma entidade étnica emergente que nasceu umbilicalmente ligada a uma sociedade e a uma cultura exógena por ela conformada e dela dependente (RIBEIRO, 2006, p. 335):

São Paulo surge, por isso, com uma configuração histórico-cultural de povo novo, plasmada pelo cruzamento de gente de matrizes raciais díspares e pela integração de seus patrimônios culturais sob a regência do dominador que, ao longo termo, imporia a preponderância de suas características genéticas e de sua cultura (RIBEIRO, 2006, p. 335).

\footnotetext{
${ }^{4}$ Darcy Ribeiro (2006, p.72) afirma que isso se alcançava graças ao sistema de parentesco classificatório dos índios, que relaciona, uns com os outros, todos os membros de um povo. Assim é que, se aceitando a moça, o estranho passava a ter nela sua temericó e, em todos os seus parentes da geração dos pais, outros tantos pais ou sogros. O mesmo ocorria em sua própria geração, em que todos passavam a ser seus irmãos ou cunhados. Na geração inferior eram todos seus filhos ou genros. Nesse caso, esses termos de consanguinidade ou de afinidade passavam a classificar todo o grupo como pessoas transáveis ou incestuosas.
} 
Apesar da clara preferência de Ribeiro pelo indígena na composição étnica do brasileiro, durante o período colonial, o autor não deixa de apontar a importância dos africanos. Entretanto, destaca que a contribuição cultural do negro foi pouco relevante na formação daquela protocélula original da cultura brasileira:

Apesar do seu papel como agente cultural ter sido mais passivo que ativo, o negro teve uma importância crucial, tanto por sua presença como massa trabalhadora que produziu quase tudo que aqui se fez, como por sua introdução sorrateira, mas tenaz e continuada, que remarcou o amálgama racial e cultural brasileiro com suas cores mais fortes (RIBEIRO, 2006, p. 102).

O antropólogo defende que a diversidade linguística e cultural dos povos africanos introduzidos no Brasil, somado à hostilidade recíproca que eles traziam da África e à política de evitar a concentração de escravos oriundos de uma mesma etnia, nas mesmas propriedades, impediu a formação de núcleos solidários que retivessem o patrimônio cultural africano. Deste modo, os negros teriam sido compelidos a incorporar-se passivamente no universo cultural da sociedade colonial. Isto não impediu, no entanto, que o nordeste açucareiro e as regiões mineradoras do centro do país fossem profundamente afetadas pela população negra, seja pela feição africana, seja pelas “cadências e ritmos e nos sentimentos especiais de cor e de gosto” (RIBEIRO, 2006, p. 103).

Para entender o que acontece com o negro no Brasil colonial, de acordo com o pensamento de Ribeiro, é necessário observar como o autor opera com dois conceitos fundamentais em sua obra, deculturação e aculturação. A deculturação tem como elementos básicos: seu caráter compulsório expresso no esforço por inviabilizar a manifestação da cultura própria e por impossibilitar sua transmissão; e sua natureza de procedimento deliberado de incorporação de pessoas já integradas numa tradição em um novo corpo de compreensões comuns, tendente a cristalizar-se como uma nova cultura. A deculturação é uma primeira instância do processo mais geral, a aculturação, que opera tanto pelo desenraizamento como pela criatividade cultural, pelos quais as etnias se conformam e se transfiguram. "Esta transfiguração torna-se imperativa para as populações deculturadas dada a necessidade de plasmar novos corpos de compreensões comuns e co-participadas para viabilizar o convívio humano e a participação na vida social” (RIBEIRO, 1978, p. 131). Portanto, as situações típicas de aculturação ocorrem em culturas em cristalização, 
representadas por protocélulas nas quais se fundem conteúdos das tradições culturais díspares e novos elementos culturais se criam, como ocorria no período colonial brasileiro.

Deste modo, o negro aparece, em Darcy Ribeiro, como um agente da europeização, visto que, após sua deculturação e subsequente aculturação no novo universo cultural da colônia, passava a difundir a língua do colonizador, ensinaria aos recém-chegados as técnicas de trabalho, as normas e os valores próprios da subcultura a que se via incorporado. Nesse sentido, o escravo é visto como um indivíduo quase passivo dentro da sociedade ao qual foi inserido, mantendo muito pouco de sua cultura original e fadado a propagar a cultura de seu opressor.

Os resquícios da cultura negra estariam principalmente no plano ideológico, "porque ele era mais recôndido e próprio” (RIBEIRO, 2006, p. 105). Portanto, seria nas crenças religiosas e nas práticas mágicas que residiria a herança dos negros, bem como nas reminiscências rítmicas e musicais e nos saberes e gostos culinários.

Percebe-se, com isso, que, mesmo vendo o Brasil como um país mestiço, Ribeiro acredita em uma miscigenação mais intensa e mais importante entre brancos e índios, seja no plano biológico, seja no plano cultural. O mameluco é o grande cerne da nacionalidade, enquanto o negro, e em consequência seus descendentes, perde sua cultura ao ser inserido como escravo na colônia.

Por isso, Darcy Ribeiro afirma que os neobrasileiros, primeiros habitantes dos núcleos coloniais, possuíam feições indígenas. Segundo o autor, a população básica destes núcleos, por muito tempo, exibiria uma aparência muito mais indígena que negra ou europeia, "pelo modo como moravam, pelo que comiam, por sua visão do mundo e pelo idioma que falavam” (RIBEIRO, 2006, p. 109). No caso da língua, por exemplo, teria sido utilizado o idioma tupi até meados do século XVIII. A contribuição cultural do indígena para a sociedade colonial também se fazia sentir no nível tecnológico, com o cultivo e preparo da mandioca, do milho, da abóbora e das batatas, e de muitas outras plantas, além das técnicas indígenas de caça e pesca. Essa visão de adaptação do europeu aos costumes e práticas indígenas em muito se aproxima das ideias de Sérgio Buarque de Holanda (1902-1982), em Caminhos e Fronteiras $(1957)^{5}$.

\footnotetext{
${ }^{5}$ Sérgio Buarque de Holanda destacou a capacidade de adaptação como traço característico dos portugueses, afirmando que o movimento das bandeiras deve ser entendido por meio desse traço cultural. No pensamento deste autor, a comunicação com o indígena, bem como a mestiçagem com o gentio teriam sido fatores fundamentais para a colonização portuguesa na América: "Influência que viria a animar, senão tornar possível, as grandes empresas bandeirantes” (HOLANDA, 1994, p. 21).
} 
Ribeiro resume a participação de índios, negros e brancos na formação dos povos novos da América da seguinte forma:

O indígena contribuiu, principalmente, na qualidade de matriz genética e de agente cultural que transmite sua experiência milenar de adaptação ecológica às terras recém-conquistadas. $\mathrm{O}$ negro, também como matriz genética, mas principalmente na qualidade de força de trabalho geradora da maior parte dos bens produzidos e da riqueza que se acumulou e se exportou e, ainda, como agente da europeização, que assegurou às áreas onde predominava uma completa hegemonia linguística e cultural europeia. O branco teve papel de promotor da façanha colonizadora, de reprodutor capaz de multiplicar-se prodigiosamente, de implantador das instituições ordenadoras da vida social; e, sobretudo, de agente da expansão cultural que criou nas Américas vastíssimas réplicas de suas pátrias de origem, linguística e culturalmente muito mais homogêneas que elas próprias (RIBEIRO, 1978, p. 72).

No Brasil, essa mistura entre os três povos teve um promotor, as classes dominantes, que teria empreendido tal feito na busca incessante pelo lucro. Com isso, esse grupo de indivíduos é visto por Ribeiro como fazedores de gente, com uma prodigiosa capacidade de recrutar, desfazer e reformar pessoas, aos milhões. Isso ocorreu no seio de um empreendimento econômico secular, cujo objetivo estava longe de ser criar um povo autônomo, mas cujo resultado principal foi fazer surgir como entidade étnica e configuração cultural, um povo novo, ao destribalizar índios, desafricanizar negros e deseuropeizar brancos: “Ao desgarrá-los de suas matrizes, para cruzá-los racialmente e transfigurá-los culturalmente, o que se estava fazendo era gestar a nós brasileiros tal qual fomos e somos em essência” (RIBEIRO, 2006, p. 163).

Nesse sentido, indo de acordo com Adelia Maria Miglievich-Ribeiro, verifica-se em Darcy Ribeiro a ideia de que, no solo brasileiro, houve uma mistura inconfundível entre o elemento português, autóctones e africanos trazidos escravizados. Depois disso, as levas de imigração ocidental e oriental não puderam mais garantir o retorno à suposição de pureza que, mesmo sem lastro na realidade, em seu território de origem buscavam, de algum modo, ostentar:

Ao estudar a pluralidade dos modos de ser dos sertanejos nordestinos, dos caboclos da Amazônia, dos crioulos do litoral, dos caipiras do sudeste e do centro do país, dos gaúchos das campanhas sulinas, dos ítalo-brasileiros, dos teuto-brasileiros, Darcy confirmava que, no Brasil, o elemento híbrido reina (MIGLIEVICH-RIBEIRO, 2011, p.10). 
Assim, Darcy Ribeiro percebe, no período colonial, a gestação do povo brasileiro, um povo novo por ter surgido do entrelaçamento de três matrizes raciais adversas. Mesmo, dando uma maior ênfase ao mameluco, mestiço de índio com branco, na nossa formação étnica, o autor não deixa de expor a contribuição do negro, ainda que este tenha sido desraizado de seu passado africano e tenha se tornado um agente da europeização. A identidade brasileira surgiria após esse contato físico, por um sentimento de ninguendade vivido, principalmente, por brasilíndios e afro-brasileiros, assunto sobre o qual nos debruçaremos nas linhas que se seguem.

\section{Miscigenação e identidade em Darcy Ribeiro}

Antes de entrarmos diretamente na questão da identidade na obra de Darcy Ribeiro, achamos necessário fazer algumas breves considerações acerca deste conceito. De acordo com Sandra Jatahy Pesavento, enquanto representação social, a identidade é uma construção simbólica de sentido, que organiza um sistema compreensivo pela ideia de pertencimento. Segundo a autora, a identidade é uma construção imaginária que produz a coesão social, permitindo a identificação da parte com o todo, do indivíduo frente a uma coletividade, e estabelece a diferença. “A identidade é relacional, pois ela se constitui pela identificação de uma alteridade. Frente ao eu ou ao nós do pertencimento se coloca a estrangeiridade do outro" (PESAVENTO, 2008, p. 90).

Nesse sentido, o antropólogo Fredrik Barth afirma que um grupo mantém sua identidade quando seus membros interagem com os outros. Disso decorre a existência de critérios para determinação do pertencimento, assim como as maneiras de assinalar este pertencimento ou exclusão. Portanto, a identidade implica o compartilhamento de critérios de avaliação e de julgamentos:

Por outro lado, a dicotomização que considera os outros como estranhos, ou seja, membros de outro grupo étnico, implica o reconhecimento de limitações quanto às formas de compreensão compartilhadas, de diferenças nos critérios para julgamento de valor e de performance, bem como uma restrição da interação àqueles setores em que se pressupõe haver compreensão comum e interesses mútuos (BARTH, 2000, p.34).

Deste modo, as identidades delimitam o pertencimento, apontando exigências de atuação para seus membros. 
Em Darcy Ribeiro, o tema identidade aparece, principalmente, como identidade étnica. No caso da América Latina e do Brasil, que nos interessa, o processo de formação da identidade étnica está intimamente ligado ao conceito de atualização histórica, que opera por meio da dominação e do avassalamento de povos estranhos, seguida da ordenação econômico-social dos núcleos em que se aglutinam os contingentes dominados para o efeito de instalar novas formas de produção ou explorar antigas atividades produtivas (RIBEIRO, 1983, p.36).

Na primeira etapa desse processo, prevaleceram a dizimação proposital de parcelas da população agredida e a deculturação dos contingentes avassalados. Na segunda etapa, tem lugar certa criatividade cultural que permite plasmar, com elementos tomados da cultura dominadora e da subjugada, um corpo de compreensões comuns, indispensável para possibilitar o convívio e orientar o trabalho. Tal se dá através da criação de protocélulas étnicas que combinam fragmentos dos dois patrimônios dentro do enquadramento de dominação. Numa terceira etapa, estas células passam a atuar aculturativamente sobre o seu contexto humano de pessoas desgarradas de suas sociedades originais, atingindo tanto os indivíduos da população nativa, quanto os contingentes transladados como escravos e, ainda, aos próprios agentes de dominação e aos descendentes de todos eles (RIBEIRO, 1983, p.36).

Portanto, é esse processo de dominação dos povos europeus sobre as sociedades americanas que proporcionaria o surgimento de identidades comuns entre os sujeitos subjugados. Deste modo, a constituição dessa identidade seria o grande desafio enfrentado pelos povos novos, que estavam se fazendo com uma configuração totalmente diferente de suas matrizes.

Segundo Pedro Abib, o mestiço, elemento fundamental da configuração étnica brasileira, aparece na obra de Darcy Ribeiro como uma nova etnia, com particularidades e especificidades diferentes em relação ao índio, ao negro e ao branco. Essa nova etnia surge da necessidade de diferenciação destes mestiços frente aos seus ascendentes, gerando um persistente esforço de elaboração de sua própria imagem e consciência, fazendo surgir, pouco a pouco, a brasilidade (ABIB, s/d, p. 5-6).

Assim, a identidade de brasileiro, na perspectiva do antropólogo mineiro, teria surgido a partir do estranhamento, sobretudo com relação aos europeus:

É bem provável que o brasileiro comece a surgir e a reconhecer-se a si próprio mais pela percepção de estranheza que provocava no lusitano do que por sua identificação como membro das comunidades socioculturais novas, 
porventura também porque desejoso de remarcar sua diferença e superioridade frente aos indígenas (RIBEIRO, 1978, p.114).

Deste modo, para Ribeiro, o brasilíndio, ou mameluco, assim como o afro-brasileiro existiam numa terra de ninguém, etnicamente falando, e é a partir dessa carência essencial, para livrar-se da ninguendade de não índios, não europeus e não negros, que eles se veem forçados a criar a sua própria identidade étnica: a brasileira (RIBEIRO, 1978, p.118). Nas palavras de Adélia Miglievich Ribeiro, se nascemos ninguém, recusando a mãe índia ou a mãe preta e rejeitados pelo pai português, é dialeticamente de nossa niguendade, do não ser, que os brasileiros se ergueram como um dos povos hoje mais homogêneos linguística e culturalmente e, também, um dos mais coesos socialmente do ponto de vista de não se abrigar aqui, por exemplo, nenhum contingente separatista (RIBEIRO, 2009, p. 65).

Portanto, a identidade brasileira surge a partir do sentimento de exclusão. De acordo com Pesavento, a exclusão é uma condição atribuída que nasce do gesto, da palavra e do olhar de quem designa o outro: "Ela se faz acompanhar da rejeição, do estigma e do preconceito, negando um lugar social de reconhecimento a este outro" (PESAVENTO, 2008, p. 92). Nesse sentido, como ocorre no Brasil de Darcy Ribeiro, os excluídos podem experimentar processos reativos a esse fenômeno de rejeição, articulando identidades próprias, face ao mundo dos incluídos que os rechaça.

Com isso, Darcy Ribeiro acredita que o primeiro brasileiro consciente de si teria sido o mameluco, que sofria com a rejeição tanto por parte dos europeus quanto por parte dos indígenas. De acordo com João Azevedo Fernandes, os brasilíndios representavam para Ribeiro os primeiros brasileiros, não por meio da construção de uma identidade, mas precisamente pela ausência de qualquer identidade. Por um lado, a noção Tupinambá de concepção considerava a criança como um fruto exclusivo do pai, o que afastava os brasilíndios de seus parentes maternos. Por outro, estes mestiços eram desprezados pelos europeus, que não viam muitas diferenças entre os mamelucos e os próprios índios. "É esta "ninguendade”, esta ausência, que forçará o surgimento de uma nova identidade, a brasileira” (FERNANDES, 2004, p. 166-167). Portanto:

(...) não podendo identificar-se com os que foram seus ancestrais americanos - que ele desprezava -, nem com os europeus - que o desprezavam -, e sendo objeto de mofa dos reinóis e dos luso-nativos, via-se condenado à pretensão de ser o que não era nem existia: o brasileiro (FERNANDES, 2004, p. 114). 
Por outro lado, esse sentimento de rejeição também era sentido entre os filhos de pais brancos nascidos no Brasil. Ocupavam, em sua própria sociedade, uma posição inferior em relação aos que vinham da metrópole e se vexavam da sua condição de filho da terra, recusando o tratamento de nativo e discriminando o brasilíndio mameluco ao considerá-lo índio.

Já os descendentes de africanos, os mulatos, tinham de se sentir ou brasileiros ou nada, visto que a identificação com o índio, com o africano ou com o brasilíndio era impossível. “Além de ajudar a propagar o português como língua corrente, esses mulatos, somados aos mamelucos, formaram logo a maioria da população que passaria, mesmo contra sua vontade, a ser vista e tida como a gente brasileira” (FERNANDES, 2004, p. 115).

Com isso, percebe-se que a identidade étnica brasileira, na perspectiva de Darcy Ribeiro, surge, principalmente, pelos frutos da miscigenação. São os mamelucos e os mulatos os grandes impulsionadores de um sentimento novo, o sentimento de ser brasileiro. Ao se sentirem excluídos por seus ascendentes, não podendo compartilhar de sua identidade, se veem obrigados a criar algo novo. Assim, a mestiçagem intensa no Brasil, ao criar homens desenraizados, foi a propulsora de uma nova identidade e o elemento essencial para criar o povo novo brasileiro:

O surgimento de uma etnia brasileira, inclusiva, que possa envolver e acolher a gente variada que aqui se juntou, passa tanto pela anulação das identificações étnicas de índios, africanos e europeus, como pela indiferenciação entre as várias formas de mestiçagem, como os mulatos (negros com brancos), caboclos (brancos com índios) ou curibocas (negros com índios) (RIBEIRO, 2006, p. 119).

Nesse processo, todos os grupos se tornam uma gente só, que se reconhece como igual em alguma coisa tão substancial que anula suas diferenças e os opõe a todas as outras gentes. "Dentro desse novo agrupamento, cada membro, como pessoa, permanece inconfundível, mas passa a incluir sua pertença a certa identidade coletiva” (RIBEIRO, 2006, p. 120).

Assim, como afirma Lucas Miranda Pinheiro (2006, p. 172-173), para Ribeiro a principal referência para a reinvenção étnico-cultural dos povos latino-americanos não é a predominância da cultura ibérica na definição de sua identidade, mas a mestiçagem, a ideia de uma civilização, por essência, multicultural, mestiça e híbrida. São os mestiços, portanto, que desencadeiam, por meio da rejeição, um sentimento novo, uma nova identidade, que os transformam de ninguém (nem brancos, nem negros, nem índios) em algo original, o brasileiro. Mais adiante, após um esforço persistente de autoafirmação política com a 
finalidade de conquistar sua autonomia e se impor um projeto próprio de existência, esta proto-etnia viria a se tornar uma etnia nacional. Com isso, o caráter nacional apenas surge após a correspondência entre a autoidenticação de um grupo com uma comunidade humana em si, diferenciada de todas as demais, e a existência de um estado e governo próprios, em cujo quadro essa etnia passa a viver seu destino (RIBEIRO, 1983, p. 36-37).

\section{Considerações Finais}

Ao analisarmos a obra de Darcy Ribeiro, percebemos que o Brasil representado pelo autor é um Brasil mestiço, híbrido, miscigenado. Fruto da colonização Ibérica e da mistura de povos distintos, é o exemplo claro de um povo novo, diferente de suas matrizes originais.

No entanto, podemos perceber em Ribeiro, talvez devido a sua experiência como antropólogo, uma clara preferência pelo mameluco, mestiço de índio com branco. Nele estava o primeiro brasileiro, o brasilíndio, que teve em São Paulo seu principal berço, facilitado pela instituição do cunhadismo. Nota-se uma valorização extrema da cultura indígena na formação do Brasil. O europeu, ao desembarcar nas terras brasílicas teria se aproveitado de diversos conhecimentos dos ameríndios em benefício próprio, o que teria facilitado na sua adaptação aos trópicos.

Já os negros foram desgarrados de sua cultura de origem, sendo obrigados a deixarem de lado a cultura africana e a absorverem a cultura da sociedade colonial. Desse modo, se tornaram agentes da europeização na América, ajudando na propagação da língua e dos costumes dos colonizadores. Assim, Darcy Ribeiro deixa para o mulato um papel secundário na formação do povo brasileiro, ao contrário do que faz o pernambucano Gilberto Freyre.

Todavia, foi a miscigenação entre os três povos que possibilitou o surgimento da identidade brasileira. O mestiço é o grande responsável pela origem do sentimento de ser brasileiro, ao se identificar como um ninguém e ter de criar algo novo, a brasilidade. Portanto, se para Fredrik Barth a identidade surge da interação com o outro, no Brasil essa interação teria se traduzido em rejeição do outro. Ao não ser nem português, nem índio e nem negro, os mestiços tiveram de criar novos critérios de pertencimento dentro do mundo colonial, gerando uma etnia singular que eliminaria o sentimento de ninguendade.

É necessário frisar, no entanto, que as ideias de Ribeiro foram, por várias vezes, questionadas no mundo acadêmico pelo seu caráter romantizado. Por outro lado, apesar do livro ter sido escrito em 1995, as obras utilizadas na bibliografia do autor são, em sua maioria, anteriores à década de 1980, ou seja, Ribeiro deixou de incorporar toda uma produção 
acadêmica que buscava Renovar os temas escravidão e mestiçagem no Brasil, a partir dos anos 80. Tal postura comprometeu a aceitação do livro entre historiadores e antropólogos dispostos a romper com padrões de análise "ultrapassados” e "idealizados" sobre a realidade nacional.

Num momento onde o modelo de interpretação marxista estava sendo questionado entre diversos intelectuais, sobretudo após a dissolução da URSS na década de 1980, Darcy Ribeiro manteve-se fiel ao padrão de análise que lhe consagrou nos anos 60 e 70 como um dos principais intelectuais de esquerda na América Latina. Deste modo, o autor não se esforçou em atualizar seu pensamento ou adequá-lo às novas exigências da academia, o que lhe rendeu diversas críticas.

Isto, no entanto, não pode retirar a importância do trabalho de Darcy Ribeiro para o pensamento social brasileiro. Apesar de todas as ressalvas que se pode fazer a sua produção, o autor realizou uma interpretação singular do Brasil, dando especial atenção às misturas raciais como definidoras de nossa identidade. Nas palavras de Helena Bomeny (2009, p. 348), a obra de Darcy reafirma as possibilidades originais de uma civilização que, no Brasil, combina a seu favor a mistura, os imponderáveis e a plasticidade da interação interétnica.

\title{
THE NEW BRAZILIAN PEOPLE: miscegenation and identity in the Darcy Ribeiro's thought
}

\begin{abstract}
This article examines the work of Darcy Ribeiro, principally the book O Povo Brasileiro (1995). It is focusing about the relationship between miscegenation and identity according to the thought of the author. We try to understand how the Brazil is identified as a new people, a singular ethnic identity arising from the mixture of different peoples with different racial, cultural, linguistics characteristics. Thus, the intense mixing, biological and cultural, is the fundamental element to understand the formation of the Brazilian people, moreover, these are determinant to the formation of the specific ethnic identity of the Brazilian people.
\end{abstract}

Keywords: Darcy Ribeiro. Miscegenation. Identity.

\section{Referências}

ABIB, Pedro Rodolpho Jungers. A mestiçagem como processo de re-significação de identidades. Disponível em:

<http://www.grupomel.ufba.br/textos/download/mesticagem_como_um_processo_de_resignif icacao_de_identidades.pdf $>$. Acesso em: 19 dez. 2011. 
BARTH, Fredrik. O guru, o iniciador e outras variações antropológicas. Rio de janeiro: Contra Capa Livraria, 2000.

BOMENY, Helena. Aposta no futuro: o Brasil de Darcy Ribeiro. IN: BOTELHO, André; SCHWARCZ, Lilia Moritz (Orgs.). Um enigma chamado Brasil: 29 intérpretes e um país. São Paulo: Companhia das Letras, 2009.

FREYRE, Gilberto. Casa Grande e Senzala: formação da família brasileira sob o regime da economia patriarcal. Rio de Janeiro: Record, 1990.

FERNANDES, João Azevedo. Violência e mestiçagem: a origem da família brasileira na obra de Darcy Ribeiro. IN: Revista ANTHROPOLÓGICAS, ano 8, volume 15 (1): 155-183 (2004), disponível em:

<http://www.ufpe.br/revistaanthropologicas/index.php/revista/article/view/35>, acesso em: 19 dez. 2011.

HOLANDA, Sérgio Buarque de. Caminhos e Fronteiras. São Paulo: Companhia das Letras, 1994.

MIGLIEVICH-RIBEIRO, Adelia Maria. A crítica pós-colonial a partir de Darcy Ribeiro: Uma releitura de O Povo Brasileiro. IN: REALIS - Revista de Estudos Antiutilitaristas e Poscoloniais, v. 1, n. 1, 2011.

PESAVENTO, Sandra Jatahy. História e História Cultural. Belo Horizonte: Autêntica, 2008.

PINHEIRO, Lucas Miranda. Darcy Ribeiro e a América Latina: um pensamento em busca da identidade e da autonomia latino-americanas. Franca: Universidade Estadual Paulista "Julio de Mesquita Filho” (UNESP), Dissertação de Mestrado (História), 2006.

RIBEIRO, Adélia M. A antropologia dialética de Darcy Ribeiro em “O povo brasileiro”. IN: SINAIS - Revista Eletrônica - Ciências Sociais. Vitória: CCHN, UFES, Edição n.06, v.1, Dezembro. 2009, pp. 52-72.

RIBEIRO, Darcy. O Povo Brasileiro: a formação e o sentido do Brasil. São Paulo: Companhia das Letras, 2006. . As Américas e a Civilização: Formação histórica e causas do desenvolvimento desigual dos povos americanos. Petrópolis: Vozes, 1983. Os Brasileiros: Livro I - Teoria do Brasil. Petrópolis: Vozes, 1978. 